\title{
Bir Siyasî İçecek Olarak Türk Kahvesi*
}

\author{
Doç. Dr. Ali Çaksu \\ Yıldız Teknik Üniversitesi, Fen Edebiyat Fakültesi \\ Insan ve Toplum Bilimleri Bölümü \\ alicaksu@yahoo.com
}

Öz

Son yıllarda, yiyecek ve içeceklerin siyasetle olan yakın ilişkisini ortaya koyan ilginç çalışmalar yürütülmektedir. Öncelikle, birçok yiyecek ve içecek kendi tarihlerine sahip olup, bunlardan bazıları farklı coğrafyalarda yayılırken oralarda kültür, ekonomi, dînî hayat ve siyaseti etkileyip kendileri de bunlardan etkilenmektedirler. Türk kahvesi, kıtanın güneydoğu ucundaki İstanbul'a ulaşmasından bu yana, Avrupa'da bir içecek ile siyaset ve dînî kültür arasındaki ilişkiye çok çarpıcı ve renkli bir örnek teşkil etmektedir. Kanaatimce, Türk kahvesi daha en başta (16. yüzyıl ortalarında) İstanbul'da "siyası̂” bir içecekti veya bir başka deyişle siyasîleştirildi, çünkü bu içeceğe ve tüketildiği mekanlara çoğu zaman siyasî anlamlar yüklendi. Makalenin ilk kısmı kıtaya yeni gelen bir içeceğin (Türk kahvesinin) hem Osmanlı başkentinde hem de Hristiyan Avrupa'da nasıl devleti, siyaseti ve dini ilgilendirdiğini gösteriyor. Böylece bu kısım daha çok, bir içeceğin girdiği ülkelerde siyaset ve kültürü etkilemesi hakkındadır. Buna karşılık, makalenin ikinci kısmı ise tam tersini yansitıyor: Yunanistan ve Bosna örneklerinde ise siyasetin kendi davası için gastronomi dahil, gündelik hayatı nasıl biçimlendirdiğine şahit oluyoruz. Bu kısım, 20. yüzyıl sonlarında siyaset ve milliyetçilik dolayısıyla, Türk kahvesinin isim olarak Yunan ve Boşnak kahvesine dönüştüğü iki örnek üzerinde durmaktadır. Burada basit bir içeceğin sadece millî bir ad alarak bir millî kimlik ve gurur nesnesi ve aracı olduğunu görüyoruz. Kısacası kahve, 20. yüzyılda bir defa daha, sıradan bir içecek olmaktan çıkarak siyasî bir içecek olmuş ve birçok insanın kimliğinin bir parçası haline gelmiştir. Kahve ve kahvehanenin toplum ve siyasetle ilişkisini de içeren tarihi son yıllarda önem kazanan maddî tarih alanına ilginç ve önemli bir örnek teşkil etmektedir.

Anahtar Kelimeler: Kahve, kahvehane, siyaset, din, Avrupa.

\section{Turkish Coffee as a Political Drink}

\footnotetext{
Abstract

Recently, one comes across interesting publications on the close relationship between some foodstuff and politics. While some foodstuff and drinks have their own histories, some of them, as they spread in different geographies, have influenced culture, economy,

* Bu çalışmanın orijinal İngilizce versiyonu yeni yayımlanmış olup künyesi şöyledir: Çaksu, Ali (2018). "Turkish Coffee as a Political Drink from the Early Modern Period to Today", From Kebab to Ćevapčići: Foodways in (Post)Ottoman Europe, eds. Arkadiusz Blaszczyk and Stefan Rohdewald, Wiesbaden: Harrassowitz, 124-143. Avrupa'da kahve, siyaset ve din ilişkisinin ele alındığı bu orijinal çalışmanın Türkçe literatürde de bulunmasını arzu ettiğimden, editörün ve yayıncının izni ile ve kendi çevirim ve uyarlamam ile bu makaleyi yayımlıyorum. 
religious life and politics and also have been influenced by them. Turkish coffee provides a striking and colorful example for the relationship between a drink and politics as well as religious culture in Europe since its arrival at the southeastern-most part of the continent, namely Istanbul. I suggest that Turkish coffee was a "political drink" or was politicized in its earliest time (mid-sixteenth century) in Istanbul, because political meanings were often attached to the drink and the places where it was consumed. The first part of the present work shows how a newly introduced drink (Turkish coffee) involved the state (and politics) as well as religion both in the Ottoman capital and several parts of Christian Europe. Thus, this part is more about a drink influencing the politics and culture in the lands where it spread. Yet, the second part of the work reflects just the reverse, that is, how politics shapes to its purposes the everyday language, including gastronomy, as it dwells on two late twentieth-century cases in which Turkish coffee became Greek and Bosnian coffees respectively due to politics and nationalism. In the Greek and Bosnian cases, one witnesses how a simple drink, namely Turkish coffee, becomes an object of national identity and national pride by merely assuming a national name. Therefore, once again coffee became a political drink and part of the identity of many people in the $20^{\text {th }}$ century. History of coffee and coffeehouses which includes their relationship with society and politics provides an interesting and important example for the rising field of material history.

Keywords: Coffee, cafe, politics, religion, Europe. 


\section{GİRIŞ}

Son zamanlarda bazı yiyecekler ve onların kültürel ve sosyal çevreleri hakkında ilgi çekici eserler yazılıyor. Mesela, 2015 yılında yayımlanan Burek: A Culinary Metaphor [Börek: Bir Mutfak Metaforu] başlıklı bir kitap Balkanlar'da börek ve kültür arasındaki ilişkiyi ele alıyor ve hatta Sloven şovenizmine dahi atıfta bulunuyor: "Slovenya' da börek Balkanlar ve eski Yugoslav Cumhuriyetlerinden gelen göçmenler için kullanılan yüklü bir metafor oldu. Börek olmaksızın, Slovenyalı gençlerin argosunu, Sloven şovenizminin hayali dünyasını ve de sağlıklı yiyecekleri teşvik eden reklam şirketlerinin abartılı deposunu anlamak gayet zor olurdu" (Mlekuž, 2015). ${ }^{1}$ Benzeri şekilde, aynı yıl Belgrad'da düzenlenen bir konferansta, ${ }^{2}$ Dr. Dimitar Bechev Sırbistan'da tüketilen baklava ve strudelin (meyveli turta), Türkiye ve Avusturya'nın o ülkede süregelen kültürel ve siyasî etkilerinin birer sembolü olarak görülebileceğini belirtti.

Bu makalede yiyecek ve siyaset bağlamında, geçmişte ve bugün bir "siyasî" içecek olarak Türk kahvesini inceleyeceğim. Habeşistan'daki efsanevi kaynağından yola çıarak dünyanın dört bir bucağına farklı şekil ve tatlarda ulaşan kahvenin hikayesi zaten oldukça büyüleyicidir. Kahvenin hikayesini Osmanlı kültür coğrafyasında daha çarpıcı kılan yönü ise bu içeceğe ve tüketildiği bazı yerlere yüklenen siyasî anlamlardır. Göreceğimiz gibi, Türk kahvesi farklı memleketlerde oldukça siyasîleştirilmiş bir içecek idi ve hala da öyledir.

Makalede öncelikle Türk kahvesinin Osmanlı devletindeki ve özellikle İstanbul'daki siyasî karakteri üzerinde durulacaktır. Ardından, Hristiyan Avrupa'nın kahveye karşı tutumu incelenecektir. Son olarak ise, Osmanlı sonrası dönemde Türk kahvesinin siyasî sebeplerle millî adlar aldığı iki örnek (Yunan ve Boşnak kahveleri) araştırılacaktır.

İstanbul kahvehanelerinin en önemli rollerinden biri siyaset alanında idi, ki bu da onları sık sık yetkililerin hedefi haline getirdi. Kaynaklarda "devlet sohbeti" olarak adlandırılan siyasî tartı̧malar çoğu zaman kahvehanelerde gerçekleşiyordu. Bu tür "sohbet"ler yetkilileri rahatsız ediyordu, zira sıradan insanlar üzerindeki olası etkilerinden dolayı yetkililer onlara şüpheyle bakıyor ve onları mevcut düzene bir tehdit olarak algiliyorlard.$^{3}$ Devlet sohbetlerinde belirli bir Paşanın yolsuzluğundan tutun da, kabine değişiklikleri ve savaş ihtimaline kadar birçok konuda dedikodu ve söylentilere rastlamak mümkündü. Okur-yazar insanların sayısının gayet az olduğu bir çağda, söylentiler en önemli iletişim araçlarından biri olup kamuoyunu etkileme ve yönlendirme gücüne sahipti. Halbuki o devirde halkın siyasî konular hakkında bir fikrinin olması kabul edilebilir bir şey değildi. Bu yüzden, genellikle siyasî olmayan gerekçeler kullanan yetkililer kahvehaneleri sık sık kapattılar. Ünlü tarihçi Naîmâ'nin kahvehaneler hakkındaki şikâyetleri aslında kahvehanelere tepeden bakan resmi tavra güzel bir örnektir. Bu tarihçiye göre, kahvehaneler halkın makam sahibi insanları eleştirmek ve devlet işleri, tayinler ve aziller hakkında asılsız söylentiler çıkarmak için toplandığı yerlerdi. İște 4 . Murat da bu tür toplantılar fitneye sebep

\footnotetext{
$\overline{1}$ Yazarın aynı konu hakkındaki doktora tezine (Mlekuž, 2008) (sonunda uzunca bir İngilizce özetle birlikte) internetten ulaşılabilir. Ayrıca, aksi belirtilmediği takdirde, bu makaledeki çevirilerin hepsi bana aittir.

2 "Turkey and Serbia in the 21st Century", Belgrad, Sirbistan, 16 Nisan 2015. Konferans Ankara'daki SETA Vakfi'na ait olan Insight Turkey adlı akademik dergi tarafından Belgrad Üniversitesi Siyasal Bilimler Fakültesi ile işbirliği ile düzenlendi. Konferans hakkında bilgi için, bkz. Ünal (2015).

${ }^{3}$ Devlet "devlet sohbeti" ne pek müsamaha göstermedi. Devlet sohbetine karışanlar, ki bunların arasında çok sayıda Yeniçeri vardı, çoğunlukla sürgüne gönderildi. Hatta bir keresinde, hamamda siyaset tartıştıkları için birkaç kadın hapse atıldı. Yetkililer devlet sohbetinin yapıldığı mekanları da cezasız bırakmayıp çok sayıda berber dükkanı ve kahvehaneyi kapattılar (Câbî, 2003: s. I/392).
}

SEFAD, 2019; (41): 369-386 
olmasın diye, gece gündüz şehri teftiş etti ve tütün ve kahve içenleri sıkı kontrol altında tutmaya çalıştı. Hatta bu husustaki hoşnutsuzluğu kahvehanelerin yıkılmasını emretmeye kadar vardı (Naîmâ 1281-83: s. III/171). Hatta 16. yüzyılda kahve İstanbul'a ilk geldiğinde, "genellikle siyasî sebeplerden dolayı zararlı bulunmuş ve aleyhine fetvalar verilmiş̧ir" (Bostan, 2001: s. 203). Benzeri bir şikâyeti 1826 'da yazdığ1 Netîcetü'l-Vekāyi' adlı eserinde Mehmed Dâniş Bey dile getirmiştir. Ona göre, kahvehaneler (ve de bazen berber dükkanları) "asılsız söylentiler", "temelsiz konuşmalar" ve "ciddi devlet işleri hakkında çeşitli haberler" in bulunduğu yerlerdi ve bu yüzden de mecburen sık sık kapatıldılar. Ne var ki, her seferinde kahvehaneler yeniden açıldı. Kahvehaneler halk arasında o kadar rağbet görüp yaygınlaştı ki, bazı semtlerde sayıları evlerin ve diğer dükkanların sayılarını aşmaya başladı (Mehmed Dâniş, 1994: s. 74).

Kahvehanelere karşı gösterilen resmi hoşnutsuzluk ve nefret ulemanın fetvalarına da yansıdı. Örnek olarak, Şeyhülislâm Ebussuûd Efendi'nin ilk fetvası kahveyi haram saydı. Yine, başka bazı alimler meyhaneye gitmenin, kahvehaneye gitmekten daha iyi olduğunu söylediler. Öyle görünüyor ki, (belki de kafeinin etkisi dolayısıyla) bazı alimler kahveyi sarhoşluk veren bir madde olarak gördüler. İlginçtir ki, Arapça "kahva" kelimesi aslında önceleri şarap için kullanılan bir isimdi (Bostan, 2001).

Ayrıca, özellikle seçkinlere yakın olan ulema sınıfından bazı fertler, tekkelerde birtakım zikir ve ayinler sırasında kahve içiliş tarzını da yermede hiç gecikmediler. Kimi tekkelerde kahve ayinlerin bir parçası olmuştu. Geceleri yapılan ibadet, zikir, ayin ve tefekkür sırasında dervişleri uyanık tutmada yardımcı olan bu içecek çok rağbet gördü ve hatta bir tür "kutsal"lık kazandı. Bundan başka, kimi tarikatlarda, kahve fincan veya kasesini elden ele dolaştırma gibi bazı ritüeller de vardı. Kahveden bir yudum alan derviş fincan veya kaseyi yanındakine veriyor ve o da aynısını yapıyordu. Bazı sebeplerle geleneksel ulema bu tür uygulamaları "ahlaksız" bulup tenkit etti. Kısacası, kahve siyasî bakımdan suçlanan ve hakir görülen bir içecek oldu. Bu arada unutmamak gerekir ki, bazı tarikatlar siyasî iktidara yakın ve gözde iken, (Yeniçerilerin resmi tarikatı olan) Bektaşilik gibi tarikatlardan ise hiç hazzedilmiyor ve hatta bunlar yıkıcı bulunuyordu. Mesela Bektaşi tarikatı (içki içmeleri gibi sebeplerle) bazı bakımlardan gayet aykırı ve hatta çok fazla "serbest" bulunuyordu. Bu yüzden, Bektaşiler şarabın yanısıra çok miktarda kahve de içmeye başlayınca, kahve kolayca ulemanın hedefi haline geldi. Burada kahvenin, bu sefer tasavvuf bağlamında olsa da, yine siyasî çatışmanın bir araç veya nesnesi olduğunu görüyoruz.

Kahve ve kahvehanelerin siyasî yönü hakkında yaptığımız bu kısa girişten sonra, kahvehanelerin siyasî fonksiyonunun Yeniçeriler ile zirveye çıtı̆̆ı̆ı ve kahvenin en çok Yeniçeri kahvehanelerinde siyasallaştığını belirtmeliyiz. Şimdi bunun neden ve nasıl öyle olduğunu göreceğiz. ${ }^{4}$

\section{İstanbul'daki Yeniçeri Kahvehaneleri}

Yeniçeri kahvehaneleri birçok role sahne oldu. Aşağıda göreceğimiz gibi, eğlence, dedikodu, söylenti, devlet sohbeti, edebi sohbetler ve musiki icrası gibi sivillerin kahvehanelerinde yer alan alışılmış etkinliklere ilave olarak, Yeniçeri kahvehaneleri güvenlik sağlama, belediye hizmetleri görme, haraç alma, tekke vazifesi görme ve hatta

\footnotetext{
${ }^{4}$ Bu çalışmada Yeniçeri kahvehaneleri hakkında verdiğim bilgiler, büyük ölçüde şu makaleme dayanmaktadır:
} Çaksu (2007). Bu makalenin Türkçe çevirisi için bkz. Çaksu (2014). 
yatakhane olarak kullanılma gibi bazen birbirleriyle pek de bağdaşmayan bazı fonksiyonlar da icra etti.

Prensip olarak Yeniçeriler genellikle şehir halkından uzakta tutulduysa da, 196 Yeniçeri ortasından (tabur) yaklaşık 31'inin şehir içinde güvenlik ve düzeni sağlama ve belediye hizmetleri görme gibi, kendilerinin İstanbul halkı ile temasta olmalarını sağlayan görevleri vardı. Bu ortalardan herbiri başkentin semtlerinden birinde vazifeli olup bugünkü karakollara karşıllı gelen kolluklardan hizmet verdi. Genelde kollukların yanlarında Yeniçeri kahvehaneleri bulunurdu. Hatta bazen aynı bina hem kolluk hem de kahvehane olarak kullanıldı (Câbî, 2003: s. I/197, 239).

Böylece, Yeniçeriler başkentin siyasî ve kültürel hayatıyla içiçe olmakla kalmayıp devlet işlerine karışmaya da devam ettiler. Silahlı ve sık sık hoşnutsuz olan Yeniçeriler çeşitli isyanlara karıştılar ve devlet tarafından şehir içinde en başta gelen fitne ve fesat kaynağ olarak görüldüler. Buna karşılık, bazı uzmanlar, siyasî faaliyetleri bakımından, 17 ve 18. yüzyıllarda Yeniçerilerin keyfi iktidar gücüne karşı halkın yanında bir tür denge unsuru ve mutlakiyete karşı çetin bir toplumsal güç olduğunu ileri sürdüler (Kafadar, 1981: s. 70). Ancak her ne kadar şehir halkının kaygı, mesele ve şikayetlerine tercüman olup onları temsil ettiyseler de, Yeniçeriler aynı zamanda halk için sürekli bir sindirme ve zorbalık kaynağıyd $1 .{ }^{5}$

Şehirdeki sivil halkın eğlence ve edebiyat ve müzik sohbetleri gibi kültürel ve toplumsal hayatla ilgili "düzenli" kahvehane etkinliklerinin (bkz. mesela Koçu (1964: s. 297)) ötesinde, Yeniçeri kahvehaneleri bu askerlerin Bektaşiliği yaşama, şehir içinde güvenliği sağlama ve piyasayı denetleme gibi kendi kültür ve resmi görevleriyle uyumlu faaliyetlere de evsahipliği yaptı. Bunlardan başka, kahvehane hem "düzenli" fonksiyonları, hem de resmi görevleri aşan ve fitne, zorbalık ve yasadışı alanına giren faaliyetleri düzenlemeyi ve gerçekleştirmeyi mümkün kılan ideal bir mekandı.

Silahlı ve rahatsız Yeniçeriler zamanla her an patlamaya hazır ve tehdit edici bir güce dönüştü. Sultanın bu güçlü "hizmetkarları" bir kere başkaldırmaya karar verdiklerinde, sadece hükümetleri ve de sadrazamlardan kendi kumandanları olan Yeniçeri ağasına kadar üst rütbeli memurları değiştirmeye değil, sultanı da tahtından etmeye gücü yetiyordu. 18 ve 19. yüzyıllarda kahvehane Yeniçeri isyanlarıyla alakası olan mekanlardan biriydi. 1730 Patrona Halil İsyanı buna bir örnektir. Yine, 1807 Kabakçı Mustafa İsyanı'nda aktif rol oynayan Segban Başçavuşu Mustafa Ağa Atpazarı semtinde bir kahvehane işletiyordu. Aynı şekilde, Yeniçeri kahvehaneleri 1826 İsyanı'nda da olayların merkezindeydi ve birçok kahvehane sahibi bu başkaldırıdaki aktif rolleri dolayısıyla (bazıları kendi kahvehaneleri önünde olmak üzere) idam edildiler. Kısacası, Yeniçeri kahvehanesi hakkındaki resmi korku ve huzursuzluk gayet haklı ve yerindeydi.

Yukarıda değinildiği gibi, çoğu zaman yetkililer Yeniçeri kahvehanelerinden son derece rahatsızdı, ama ellerinden de bir şey gelmiyordu. 19. yüzyılda yazan Mehmed Dâniş Bey'in (1994: s. 75) bildirdiği gibi, bir Yeniçeri kahvehanesi yıkılır yıkılmaz büyük bir fitne patlıyordu. Aslında, 17. yüzyıl ortalarından itibaren, devlet bütün kahvehaneleri 
yasaklamaktansa, bir caydırma politikası güderek, ibret olsun diye ara sıra birkaç kahvehane kapatmaya başladı. Kırlı'nın 19. yüzyıl İstanbul kahvehaneleri ile ilgili araştırmasında belirttiği gibi, tamamen yasaklama yerine ibretlik cezalandırma şeklinde ortaya çıan devlet "merhamet" $i$ aslında devletin Yeniçeri kahvehanelerindeki siyasî muhalefetten korkusundan dolayı olabilir (Kırlı, 2000: s. 67).

$\mathrm{Ne}$ var ki, devletin yeniçeri kahvehanesine yönelik toleransı bir gün sona erdi. Yeniçerilerin verdiği siyasî rahatsızlığın ve halk üzerindeki insafsızlık ve zorbalıklarının sonunun gelmeyeceğini gören yöneticiler artık hiçbir ıslahatın Yeniçeri Ocağı'nı modern dünyada imparatorluğu koruyacak etkili bir askeri güce dönüştürmeye yetmeyeceğine ikna olmuştu. Bu yüzden sonunda, resmi Osmanlı tarihyazımının Vak'a-i Hayriyye (Hayırlı Olay) dediği operasyonla 1826 'da ocak trajik bir sonla ortadan kaldırıldı. Yeniçerilerin siyasî ve gayri-meşru faaliyetlerinin karargahları olarak çalışan Yeniçeri kahvehaneleri de Hayırlı Olay'da ocağın yakalandığı hayırsız kadere ortak oldu ve hepsi yıktırıldı.

Türk kahvesi kendi memleketinde toplumun değişik kesimlerinden ve özellikle de yönetici seçkinlerden gelen problemlerle karşılaşırken, başlangıçta Avrupa'da da hiç hoş karşılanmadı. İlginçtir ki, oradaki kahve karşıtlığı da bazen kendisine bir tür dînî dil seçti.

\section{"Gayri-Hristiyan" Türk Kahvesi}

20. yüzyılda bazı milliyetçi tavırlarla karşılaşmadan çok daha önceleri, Türk kahvesi Avrupa'da genelde "öteki"nin içeceği olarak görüldü ve bir tür "Hristiyan" muhalefetiyle karşılaştı. 1869 gibi geç bir tarihte bile, hayal kırıklığına uğramış bir Mark Twain (asıl adıyla, Samuel L. Clemens) bu içeceği "gayri-Hristiyan" olarak adlandırıyordu: "Bugüne kadar dudaklarımın arasından geçen gayri-Hristiyan içeceklerden en kötüsü Türk kahvesidir" (Twain, 1869). Öyle görünüyor ki, yazar burada gayri-Hristiyan ifadesiyle Hristiyan olmayan bir kültüre ait bir içeceği kastediyordu.

Ancak bazılarının kahvenin "gayri-Hristiyan" mizacını kelime anlamıyla ve oldukça ciddiye aldığı görülmekte. Kahve Hristiyan Avrupa'ya ilk girdiğinde, büyük kuşkuyla karşılandı, zira Hristiyanların asırlarca kendileriyle savaşta olduğu Müslüman kafirlerin içeceği sayılıyordu. Hatta bazı insanlar bu koyu renkli egzotik içeceği "Şeytan'ın içeceği" veya "İblis'in içeceği" olarak adlandırıyordu. Mesela, Şeytan İçeceği (Satanick Tipple) ifadesi Britanya'da yazılan Kahveye Hicviye (A Satyr against Coffee, 1674?) başlıklı şiirin daha ilk satırında geçiyordu. Bundan dolayı, kahvenin İngiliz içecek kültürüne dahil edilmesi hiç kolay olmadı. İngilizler yeni bir Türk adetine hiç de sempatiyle yaklaşmayacaktı, zira o devirde Osmanlı güçleri "Deccal'ın güçlerinin bir aracı" olarak görülüyordu (Cowan, 2005: s. 6).

Avrupa'nın büyük bir kısmında kahvenin İslam'la özdeşleştirilmesi çok uzun bir süre devam etti. Bir örnek vermek gerekirse, hem Türk kahvesi hem de Kuran tercümesi Britanya'ya aynı dönemde girdi. Yaygın olarak kabul edilen rivayetlere göre, İngiltere'deki ilk kahvehane 1650 'de Oxford'da Jacob adlı bir Yahudi tarafından açıldı. Londra'nın ilk kahvehanesi ise 1652'de Pasqua Roseé adında bir Yunan tarafından açıldı. Kuran'ın İngilizceye bilinen en eski tercümesini ise Kral 1. Charles'in özel rahibi Alexander Ross 1649 'da yaptı. The Alcoran of Mahomet (Muhammed'in Kuran'1) başlıklı bu çeviri aslında Malezair lordu Sieur du Ryer'in yaptığı L'Alcoran de Mahomet (Muhammed'in Kuran'ı) başlıklı Fransızca çevirinin tercümesiydi. Bu yüzden, "Müslüman" bir içecek olan kahve ile Kuran'ın hemen hemen aynı yıllarda Britanya'ya girişi bazılarınca ülkenin bir İslamlaşma 
tehdidiyle karşılaşması biçiminde algılandı. Nitekim bu algı bir şiirde açıkça dile getiriliyor (The Character of a Coffee-House, 1665):

Bir zamanlar burada kahve satılırken

Kısa süre sonra da Kuran çıkageldi:

Zira (reformcularımız öyle aptallardı ki)

Yeni içkiler yeni dinler getirdi. ${ }^{6}$

Kahvehanelerin gördüğü rağbetten dolayı kendi satışlarında düşüş gören birahane sahipleri gibi bazı insanlara göre, "Muhammed tanesi" (kahve çekirdeği) İngilizliği tehdit ediyordu: Kahve "cinsel arzuyu azaltıyordu veya artırıyordu, Müslüman olmayı teşvik ediyordu ve hatta onun İslam'ı millî bir din yapmaya yönelik 1650'lerdeki bir Cumhuriyetçi komplonun bir parçası olduğu söyleniyordu" (Maclean ve Matar, 2011: s. 202).

Alman edebiyatında da, bu sefer bir babanın kızından ricası şeklinde, bir kahve karşıtllı̆ına rastlıyoruz. Barok devrinin Alman besteci ve müzisyeni Johann Sebastian Bach'ın (1685-1750) muhtemelen 1732 ile 1735 arasında bestelediği Kaffeekantate (Kahve Kantatı) adlı bir eseri vardı. Eserden anlaşılıyor ki, 18. yüzyıl Almanya'sında kahve içmek kötü bir alışkanlık olarak görülüyordu. Eserde Bay Schlendrian kızı Liesgen'in kahve içmesini engellemeye çalışır. Fakat kızı tepki gösterir ve ona günde üç defa kahve içmek zorunda olduğunu söyler. Kız için kahve bin öpücükten daha lezzetli olup en iyi hediyedir. Bunun üzerine baba kızını tehdit eder: Eğer kahve içmeyi bırakmazsa, düğünlere gitmesine, güzel elbiseler almasına, gezintiye çıkmasına, ve hatta pencereden dışarıyı seyretmesine izin vermeyecektir. Ne var ki, bu tehditler kızı caydırmaz. Bu sefer babası onu, kahveden vazgeçmezse, evlenmesine izin vermemekle tehdit eder. Bu defa tehdit kızın karşı koyamayacağ 1 kadar güçlüdür ve kız babasının isteğini kabul etmiş görünür, ancak damat adaylarına gizlice şunu söyler: Kendisiyle evlenmek isteyen erkek kahve içmesine izin vermelidir ve bu şart evlilik sözleşmesine yazılacaktır. Hikaye "kahve içmek tabiidir" şeklinde çıkarılan bir sonuç ile biter (Bach, 2018).

Benzeri bir şekilde, bir süre sonra yine Almanya'da Karl Gottlieb Hering (1766-1853) çocuklar için yazdığı Kahve Şarkısı'nda (Kaffeelied veya Der Kaffee-Kanon) insanları (ve çocukları) bu "Türk içeceği"ne (Türkentrank) karşı uyarıyordu. Ona göre "Türk içeceği" çocuklara zararlıydı, çünkü sinirleri zayıflatıyor ve içenin benzini soldurup hasta yapıyordu. Şarkının son satırı bir uyarıyla bitiyordu: "Onu bırakamayan bir Müslüman gibi olma" (Hering, 2016).

Böylece Avrupa'da kahve uzun süre bir Türk ve Müslüman içeceği sayıldı. Britanya'da kahve çekirdeği sık sık Türk tanesi, Arap tanesi veya bazen Muhammed tanesi olarak adlandırıldı (Matar, 1998: s. 110-118). Kahveye bazen "Türk kaçak" gibi başka bazı atıflar da yapıldığına rastlıyoruz (Everard, 1672). 1852'de yazılan bir makalede, başka bir ülkede, yani kahvenin anavatanında, bazllarınca kahve hala Müslüman (ve dolayısıyla yasak) bir içecek olarak görülmekte: "Fakat, içecek sadece Müslümanlar arasında yaygın olduğundan, Hristiyan Habeşler tarafından haram sayılmaktadır..." (Crawford, 1852: s. 58).

\footnotetext{
${ }^{6}$ Bugün bile Avrupa'da benzeri tepkiler görmek mümkün. Ancak şimdi tepkiler "kebaplaşma" (kebabization) ve "İslamlaşma" tehdidine karşı. Örnek olarak, Fransa'da Béziers kasabasının belediye başkanı Robert Ménard, 2015 sonlarında kendi deyişiyle, "Yahudi-Hristiyan" değerlerini korumak için kebaba karşı bu türden bir savaş ilan etti (Chazot, 2015).
}

SEFAD, 2019; (41): 369-386 
Britanya'da Türk kahvesi üzerindeki tartışma epey sürdü. 1674'te Londralı bir kadın topluluğu Kadınların Kahve Karşıtı Dilekçesi'ni (The Women's Petition Against Coffee, 1674) yayımlayarak kocalarının kahvehanelerde çok fazla vakit geçirdiklerinden ve de evlerini ve eşlerini ihmal ettiklerinden yakındılar. Bu dilekçede de iktidarsızlık yaptığı ileri sürülen ve adına "kahve denilen bu nevzuhur ve berbat kafir içkisi" nin "kafir" karakterine denk geliyoruz. Fakat, her nasıl oluyorsa, "bu çirkin Türk cazibesi gözle görülemeyen bazı etkilerle hem zenginleri hem de fakirleri kendine cezbediyordu."

Erkeklerin kadınların dilekçesine verdiği polemik cevap (The Mens Answer to the Womens Petition, 1674) bu "zararsız ve şifalı içki"yi, yani "masum kahve"yi savunuyordu." Erkekler de Türkiye'den bahsetmekte: Bu "bütün Türkiye'de yaygın [olan] içecek"i "Şeytan'ın kutsal suyu" olarak anmaktalar, ki bu ifade kahve içilmesine karşı olanların kullandığı "Şeytan'ın içeceği" sözüne açık bir atıftır. Erkeklere göre, başka yararlarının yanında, kahve insanları "ayık" tutuyordu ve de "kahvehane yurttaşların akademisi" idi. Bu sonuncu tasvir o dönemde kahvehaneler hakkındaki yaygın bir algıyı yansıtmaktadır. Kahvehanelere bazen "peni üniversiteleri" deniyordu, zira bir erkek bir peni ücret ödeyerek bir fincan kahve alabiliyordu ve kahvehanede çeşitli konularda süren tartışmalara katılabiliyordu. Böylece, ilgi alanlarına göre, dostlarından ve yabancılardan birçok konuda bilgi edinebiliyordu.

İstanbul ve başka şehirlerde olduğu gibi, Britanya'da da kahvehanelerin siyasî etkisi yöneticiler için önemli bir problemdi. Osmanlı topraklarındaki yaygın resmi suçlama olan "fitne"yi hatırlatırcasına, Britanya'daki kahvehaneler de siyasî yıkıcılıkla özdeşleştiler. 29 Aralık 1675'te Kral Charles Londra'da bastırdığı Kahvehanelerin Kapatılmasına Dair Duyuru'da (Charles, 1675) şöyle der: “Son yıllarda kahvehanelerin çoğu... çok kötü ve tehlikeli etkiler bıraktı... Bu dükkanlarda, ve içinde toplananların katılımıyla, Haşmetli'nin hükümetini karalayan ve ülkede barış ve huzuru bozan çeşitli asılsız, art niyetli ve rezilce söylenti ve haberler uydurulmakta ve dışarıda yayılmaktadır." Ne var ki, tıpkı İstanbul'da olduğu gibi, kahvehanelerin resmen kapatılması kahveseverlerin güçlü tepkisi ve isyanı sayesinde kısa sürede başarısızlığa uğradı.

Kahve ve kahvehaneler Britanya'da ve Avrupa'da yayılmayı sürdürdü. Hatta bir zamanlar kahveye karşı ileri sürülen "dînı̂" tezlerden bazıları artık kahveyi savunan başka tür "dînı̂" tezlere yerini bırakmaya başladı: "İronik bir dönüşle, Birleşik Devletler ve Avrupa'da içkiyle savaş dernekleri meyhanelerin alkolizmine panzehir olarak kahve ve kahvehaneleri teşvik ettiler." Bir Hristiyan kafesindeki levhada şöyle bir ifade vardı: “Kahvehane-Tanrı'nın evi; Meyhane- Şeytan'ın kadehi" (Heise, 1987: s. 227).

O halde kahve nasıl "erdemli" oldu?: Kahve, alkolün tersine, bedeni uyarırken zihni açıyordu. Kahve, içenleri uyanık tutarken, alkol ise onları kasvetli ve uyuşuk yapıyordu. Kahve keskin bir zihne ve heyecanlı fikri tartışmalara katkıda bulunurken, sürekli alkol tüketimi ise şiddet riskini beraberinde getiriyordu. Kısacası, kahve insanı sarhoş etmeyip tam tersine ayık ve canlı tutuyordu.

Zamanla kahve Britanya'da toplumda kabul görürken, bazı Türk gelenek ve sembolleri de benimsenmeye başladı. Reklam yapmak ve müşteri çekmek amacıyla kimi kahvehane sahipleri sarık taktılar (Maclean ve Matar, 2011: s. 221). Londra ve Oxford'daki birçok kahvehane Türk Kafası ve Sultan'ın Kafası gibi isimler aldılar veya Koca Murat (2. Murat) gibi bazı ünlü Osmanlı padişahlarının adını taşıdılar (Cowan, 2005: s. 115). 
Kahvehane tabelalarında genellikle sarıklı bir Türk, "Türk kafası"7 ya da bir cezve veya kahve güğümü sembolü bulunurdu. Hatta bugün bile, Britanya'da bazı kafe, restoran, bar ve kulüpler Turk's Head (Türk Kafası) adını taşımaktadır. ${ }^{8}$

Bununla birlikte şunu hala merak etmek mümkün: Diğer bazı Türk yiyecek ve içecekleri daha kolaylıkla kabul görürken, kahveyi ise olumsuz algilanan bir "Türklük" ile özdeşleştirmeyi ne tetiklemiştir? Mary Priscilla Işın'a göre, şerbet Britanya'ya 17. yüzyılda ve hatta belki de daha önce girdi. İngiliz ilimadamı Francis Bacon'ın (1562-1626) (1622'de basılan) Historia Naturalis adlı eserinde şerbetten bahsettiğini biliyoruz (Işın, 2014: s. 22). Benzeri şekilde, bir başka içecek, salep de 17. yüzyılda Britanya'ya ulaştı ve 1730'lardan sonra Londra'da salep evleri (saloop houses) açılmaya başladı (Işın, 2014: s. 23). Yine, Türk lokumu da 19. yüzyıl ortalarında Britanya ve Fransa'ya ihraç edilmeye başladı ve 1870 civarında Britanya'daki ilk lokum dükkanı açıldı (Işın, 2014: s. 20). Bunlara kıyasla, kahvenin kötü şöhretinin bir sebebi zihni etkileme kapasitesi olabilir, fakat bu arada erken modern dönemdeki tıp eserlerinde kahvenin genellikle sağlığa yararlı olarak tasvir edildiğini unutmamak gerekir (Malecka, 2015: s. 184). Şu var ki, sonuçta, belki de kahvenin bir "sosyal içecek" olarak fonksiyonu ile ayık tutucu etkisinin bir araya gelmesi onu tartışmalı kıldı. Böylece, kahve fikri tartışma ve görüş alışverişi ortamlarının içeceği oldu ve özellikle başlangıçta farklı sosyal konumlardan insanları biraraya getirip kaynaştırarak kahvehanelerin yarattığı kamusal alanı yönetici seçkinler için daha tehlikeli hale getirdi (Habermas, 1991: s. 31-43; Hattox, 1996). Buna karşılık, salep ise çoğunlukla bir fakir içeceği idi ve ayrıca askerlerin beslenmesi için kullanıldı (Işın, 2014: s. 23-24). Kısacası, diyebiliriz ki, sosyal etkisi kahveyi ithal edilen öteki Türk yiyecek ve içeceklerinden daha çok eleştiriye maruz duruma getirdi.

\section{Yüzyıl Sonlarında Millî İçecek Olarak Türk Kahvesi}

Hazırlanışındaki bazı farklılıklara rağmen, Türk kahvesi Bulgaristan (Tursko kafe), Sırbistan (Turska kafa), ${ }^{9}$ Karadağ, Polonya (Kawa po Turecku) ve Çek Cumhuriyeti (Turecká kava veya turek) gibi ülkelerde aynı adla anılır ve kullanılır. Fakat bazı ülkelerde, genelde milliyetçi nedenlerle, mesela Yunanistan'da büyük ölçüde, Kıbrıs probleminden dolayı Türklere duyulan nefret yüzünden, Bosna-Hersek'te ise ulus inşa etme sürecinin bir aracı olarak, Türk kahvesinin yerini millî adlar, veya pratik nedenlerle yerel kahve veya ev kahvesi almıştır. ${ }^{10}$ Bu kısımda Balkanlar'dan iki örnek, yani Yunanistan ve Bosna-Hersek üzerinde kısaca duracağız.

\section{Yunan Kahvesi}

Balkanlar'daki Ortodoks Hristiyan seçkinlerin kahveye karşı tavrı nasıl oldu? Fotić'e (2011: s. 94) göre, "[h]iyerarşinin zirvesinin kahve tüketimine resmi olarak karşı çıktığına dair bir belirti yoktur... Tersine, kaynaklar Osmanlı seçkinlerini örnek alan Hristiyan

\footnotetext{
7 "Türk kafası" iple yapılan sarık şeklindeki süslü bir dügümdür. Adını görünüm bakımından sarı̆ga benzemesinden dolayı almıştır.

8 Sadece iki örnek verecek olursak, http://www.turksheadtwickenham.co.uk ve http://turksheadpenzance.co.uk [3.2.2016].

${ }^{9}$ Sırbistan'dan görüştüğüm bir kişiye göre, o ülkede geleneksel kahve için çoğunlukla ya Türk ya da yerel sıfatı kullanılmakta. Coffeefair Serbia vebsitesinden bir örnek verecek olursak, bu ikisi aynı anlamda kullanılıyor: “'domaća' tj 'turska'” ('evyapımı/yerel' yani 'Türk'). Ancak öyle görünüyor ki, son zamanlarda "Sırp kahvesi" de kullanılmakta.

${ }^{10}$ Burada Türk kahvesinin ne kadar "Türk" olduğu da sorulabilir. Türk kahvesi adını pişiriliş tarzından aldı. Önceleri İstanbul'a ve diğer birçok yere kahve Yemen'den ve çoğu zaman Mısır üzerinden geldi.

SEFAD, 2019; (41): 369-386
} 
seçkinlerinin yeni içeceği fazla gecikmeden benimsediğini ileri sürmekte." Aynısı tütün tüketimi için de geçerlidir. 20. yüzyıl sonlarına kadar geleneksel kahvenin "Türk kahvesi" olarak adlandırıldığı Yunanistan'da da durum farklı değildi.

Muhtemelen büyük ölçüde Kıbrıs'ta yaşanan problemler ve savaş dolayısıyla, Yunanistan'da Turkiko (Türk kahvesi) Eleniko (Yunan kahvesi) ${ }^{11}$ oldu. Yunanlılar arasındaki yaygın görüş, bu değişikliğin 1974'teki savaşın ardından geldiği şeklindedir. Ancak bu nasıl oldu? Devlet veya medya bir kampanya mı yürüttü? Belki de bu dönüşüm 1955'te Kıbrıs çatışmasının ortaya çıkışıyla başladı. Mesela, 1965'te yayımlanan gezi yazısında Britanyalı yazar George Mikes (1965: s. 29) şöyle der: '[ş]imdi Türklerle Kıbrıs konusunda çekişirlerken, Türk kahvesi de Yunan kahvesi olarak adlandırıldı;..." Öyle görünüyor ki, özellikle 1974'teki Kıbrıs'taki savaştan sonra süreç hızlandı (Browning, 1983: s. 16).

Aslında, bildiğimiz kadarıyla en azından bir kampanya vardı: Bir kahve şirketinin yürüttüğü bir medya kampanyası. 1974'te Kıbrıs'taki Türk müdahalesinin ardından, Yunan kahve şirketi Bravo "Biz Ona Yunan Diyoruz" (Emeis ton leme Elliniko) sloganı ile büyük bir reklam kampanyası başlattı ve bu girişim "Yunan" kahvesini bir kimlik sembolü yapmada başarılı oldu. ${ }^{12}$ Böylece Türk kahvesi artık Yunan kahvesi oldu ve bazı insanlar için bu adlardan birinin veya ötekisinin kullanımı genelde vatanseverleri hainlerden ayırdediyordu. Karakatsanis (2014: s. 11) bu yeniden adlandırmayı “'Türk' ile mevcut sembolik ilişkileri yok etme" sürecinin bir parçası olarak görür. Elbette ki, böylesi bir yeniden adlandırma sadece Yunanlılara özgü değildir, ancak Karakatsanis'e (2014: s. 29) göre onlara özgü olan şudur: "dilin bir yerleşik-nötür kullanımdan aktif, bilinçli, dava sahibi ve böylece siyasî bir yeniden 'adlandırma'ya hızlı ve beklenmedik etkili geçiş."

Ne var ki, Petropoulos'un kitabı O Turkikos Kafes en Eladi [Yunanistan'da Türk Kahvesi] basım yılı olan 1979'a kadar yeni adın herkes tarafından benimsenmemiş olduğunu gösterir. ${ }^{13}$ Yazar bu kitapta Yunanistan'da Türk kahve kültürü, kahvehaneler, kahvehane türleri ve ilişkili hayat tarzları, kahve tiryakileri, müşteri profilleri, kahve pişirme ve içmeyle alakalı sınıf, ritüel ve tarzlar, kahvehane araç ve gereçleri, kahve falıyla ilgili ritüel ve inançlar ve de nargile, lokum ve tavla gibi kahveye eşlik eden şeyleri inceler.

Petropoulos Yunan dilindeki kahve ve kahvehane ile ilgili terimlerin hemen hemen tamamının Türkçe kökenli olduğunu ileri sürer. Fakat ona göre, milliyetçi ve şovenist eğilimler sonucunda, Türk kahvesine Yunan kahvesi, hatta daha da gülünç olarak "Bizans kahvesi" dendi, çünkü Türk kahvesi terimi Atina'daki ırkçı ve şovenistleri rahatsız etti. Petropoulos (1995: s. 72) bunu alaylı bir biçimde dile getirir: “Bu Yunan kahvesinin ne tür bir kahve olduğunu hiçbir zaman anlayamadım. Bununla birlikte, "biz ona Yunan kahvesi diyoruz" gibi reklamların hangi faşistleri tatmin ettiğini çok iyi anlıyorum." Yazara göre, kendi küçük kitabı sayesinde Yunanistan'da Türk kahvesi ve eski kahvehaneler hakkında olumlu bir hava esti. Fakat ilginçtir ki, yazar aslında kitabının amacının "kahve ve kahvehaneler değil, modern Yunanlıların ırkçllı̆̆1" (Petropoulos, 1995: s. 85) olduğunu ilan eder.

\footnotetext{
${ }_{11}$ Aslında, 1957' den beri bir "Yunan kahvesi" zaten vardı. Frape (frappe, Greek frappé veya café frappe) adıyla tanınan bu kahve hazır kahveden yapılmış köpüklü ve buzlu bir içecekti (Tsolakidou, 2012; Young, 2013).

12 Yunanlı yazar Dimitris Fissas buradaki tuhaflı̆̆a dikkat çeker: "Zaten dünyada bu kahveye Yunan kahvesi diyen bir tek biziz." (Kırbaki, 2015).

${ }_{13}$ Ben bu kitabın ikinci (1980) baskısından yapılan Yunanistan'da Türk Kahvesi başlıklı Herkül Millas çevirisini kullandım.
} 
Günümüzde bu konu büyük ölçüde ihmal edilmiştir. Gelecekteki araştırmalar ad değişikliğinin cunta rejimi sırasında mı, yoksa daha sonra mı olduğunu ele almalıdır. 1967 ile 1974 arasında ve de demokrasiye geçişten sonra yayımlanan gazete ve literatürün taranıp incelenmesine ihtiyaç vardır. Değişimin çok kısa bir sürede olduğunu düşünmek isabetli değildir, zira çok popüler bir şeyi tepeden gelen ani bir emirle veya saldırgan bir kampanya ile değiştirmek kolay değildir.

Yeniden adlandırma nasıl olduysa olsun, kahvenin Yunan kimliğindeki önemli yeri açıkça görülür. Çarpıcı (ve de komik) bir örnek verecek olursak, Kasım 2012'de gerçekleşen bir protesto eyleminde, protestocular yabancı bir diplomatın üzerine (yumurta veya domates değil de) kahve attılar. Kemer sıkma politikalarını protesto eden birkaç kişi Selanik'te bir konferans salonunu basıp, Alman ve Yunan belediye başkanlarının buluştuğu bir toplantıya katılan bir Alman diplomata kahve attı (Miller ve diğerleri, 2012).

Şu da unutulmamalıdır ki, hem kültür hem de millî kimlik değişime açıtır. Bu bağlamda bir yazar, Yunan kahve kültürü ve kimliği arasındaki bağlantıya dikkat çeker. Ona göre, 20. yüzyıl ortalarında Yunanistan' da yaygınlaşan hazır kahve (genellikle Nescafe markası) daha çabuk kahve hazırlama yolunun ötesinde, "modernlik ve Batı dünyasının bir alameti" olarak görüldü. Yunan yiyecek yazarı Marianthi Milona için, bu tür bir hızlı kahve hazırlama tarzı Yunanlılara, Doğu dünyasından tamamen farklı olan Avrupalı kimliklerini hatırlattı (Bland, 2014).

2013'te UNESCO “Türk kahve kültür ve geleneği”ni Somut Olmayan Kültürel Miras (SOKÜM) (UNESCO, 2013) olarak kaydettiğinde, beklendiği gibi, internetteki çeşitli yorum ve resimlerden görüleceği gibi, en azından popüler düzeyde bazı Yunanlılar buna tepki gösterdi. Kimi Yunanlıların gösterdiği tepkiye şaşıran Yunan karikatürcü Vangelis Pavlidis ise şu soruyu sordu: Yunanistan'da yemeklerden tatlılara kadar Türkçe ad taşıyan düzinelerce gıda ürünü varken, bu kahve takıntımız nereden geliyor? "Neden bütün millî hüsranlarımız kahvede kendini gösteriyor? Neden özellikle kahve gizli ve açık milliyetçiliğimizin bayrağı oldu?" (Pavlidis, 2013). Bununla birlikte, UNESCO kararına Yunanistan'dan birtakım tepkiler gelse de, bazılarının (Greek Reporter, 2012) ileri sürdüğü gibi, UNESCO'yu da içine çeken Türk-Yunan “kahve savaşları"ndan bahsetmek oldukça abartılıdır. Yunanlı yazar Trivolis'in (2013) belirttiği gibi, geleneksel kahve konusunda kavga edecek bir şey yoktur: "Yunan kahvesi Türk kahvesiyle tamamen aynıdır... Süreci ve hazırlaması... Türk tarzıyla aynıdır."

\section{Boșnak Kahvesi}

Benzeri şekilde, fakat farklı sebeplerle, Bosna-Hersek'te, muhtemelen 1992-1995 yıllarındaki savaştan sonra, bu sefer Turska kafa (Türk kahvesi) Bosanska kafa (Boşnak kahvesi) oldu. 2010 ile 2016 yılları arasında yaşadığım Saraybosna'da yaptığım araştırma ve görüşmeler sonucunda bu sonuca vardık. Bildiğimiz kadarıyla, bu dönüşümün dönem ve süreci hakkında İngilizce veya Boşnakça yazılmış önemli bir çalışma yoktur. O yüzden, makalenin bu kısmında, büyük ölçüde, Saraybosna'da yaptığımız görüşmelere dayanacağız. Sayısı 20'ye yaklaşan bu kişiler hakkında kısaca bilgi vermek gerekirse, hepsi eğitimli olup çoğu akademisyendi. Bazıları köken olarak başka şehirlerden olsa da, hepsi Saraybosna'da yaşıyordu. Hiçbiri Boşnak kahvesi konusunda uzman değildi (bu konuda hiçbir yerde bir uzmana denk gelmediğimizi belirtmeliyiz). Görüşmelerimin temel sorusu Türk kahvesinin ne zaman ve nasıl Boşnak kahvesi olduğu ile alakalıydı. Elbette $\mathrm{ki}$, bu konuda daha derinlikli bir araştırmaya ve belki de ayrıntılı bir ankete ihtiyaç bulunmaktadır. 
Görüşülen kişiler arasında Türk kahvesinin isim değişikliği ile ilgili şöyle bir görüş yaygındı: Önceleri uzun bir süre ona sadece kafa (kahve) dendi, çünkü elde olan ve tüketilen tek kahve oydu. Espresso, hazır kahve ve diğer kahve türleri ortaya çıkınca, insanlar geleneksel kahveye Türk kahvesi demeye başladı. Bosna-Hersek'teki savaşa (1992-1995) kadar durum aşağı yukarı böyleydi. Ancak savaştan sonra Boşnak kahvesi terimi yaygınlaşmaya başladı.

Görüştüğüm kişilerden ikisinin dediği gibi, belki savaş öncesinde de Boşnak kahvesi terimi kulanılıyordu. Ancak diğerleri arasında ayn fikirde olmayanlar var. Mesela, Boris Sertić (42, Saraybosna) savaştan önce Boşnak kahvesi ifadesinin kullanıldığını hiç hatırlamadığını söyledi. Ona göre sadece iki ifade yaygındı: Türk kahvesi ve domaća (yani yerel kahve veya ev kahvesi). Dede ve ninesi gibi, anne ve babası da hemen hemen her zaman Türk kahvesi sözünü kullanmışlar. Nadiren ev kahvesi de demişler, o kahveyi dışarıda içilen espresso gibi kahvelerden ayırdetmek için.

Mostar'daki meşhur Eski Köprü yakınındaki bir kahvehane sahibi menüsünde hala Türk kahvesi ifadesini kullanıor. Kendisine sebebi sorulduğunda şöyle cevap vermekte: Yugoslavya döneminde bu kahveyi içen herkes ona Türk kahvesi dedi (Türkleri sevse de, sevmese de). Ona Boşnak, Hırvat veya Sırp kahvesi demek saçma olurdu, zira herkes bu tür kahvenin kökenini ve adını biliyordu.

Son olarak, yaygın olmayan bir görüşten bahsedelim. Adı bizde mevcut bir akademisyene göre, savaştan önce, yani Yugoslavya döneminin sonlarında Türk kahvesine evlerde Boşnak kahvesi, kafelerde ise Türk kahvesi dendi. Fakat görüştüğümüz diğer kişilere bu görüşü de sorduğumuzda, aynı fikirde olan hiç kimse çıkmadı.

Bir başkası, mesai arkadaşım Nermina Zildžo (69, Saraybosna) ise Yugoslavya'da kahvenin telaffuzu ile ilgili bir noktaya dikkatimi çekti. Bir süre kahveye Sırbistan'da "kafa", Hırvatistan'da "kava", Bosna' da ise "kahva" dendi (farklı adlar taşımasına ve aralarında bazı farklar bulunmasına rağmen, bu üç ülkedeki resmi ve hakim dillerin aynı dil olduğunu belirtelim). Öyle görünüyor ki, farklı etnik-dînî grupların kendi telaffuz biçimleri vardı ve Bosnalılar kahvenin Arapça ve Türkçe aslına daha yakın olan telaffuzunu tercih ettiler. Sonraları "kafa" Bosna'da da hakim oldu ve bugün en yaygın olan kelimedir. Bununla birlikte, bazı yaşlı Bosnalıların ve dindar insanların hala "kahva" yı tercih ettiğini görmek mümkündür.

Bugün Bosna Hersek'te hemen her yerde birçok Bosnalı Boşnak kahvesi terimini gururla kullanmaktadır. Boşnak kahvesinin şimdi bir millî kimlik ve gurur nesnesi olduğuna şahit oluyoruz (Cohen, 2014). “Kahve kültürü Bosnalıların bilincinde kök salmıştır. Bosnalılar kahvenin kimliklerinin ayrılmaz bir parçası ve sosyal dokularının temeli olduğunu söylerler" (Halevy, 2011: s. 68). Kahve en azından Boşnaklar için, ulus inşa etme sürecinde küçük fakat güçlü bir faktördür. Birçok Boşnak kahvelerinin Türk kahvesi olmadığını ve Boşnak kahvesinin biraz farklı hazırlandığını vurgular, ki bu ikinci ifade doğrudur. Ancak şuna dikkat etmelidir ki, Türk kahvesi diğer ülkelerde de her zaman aynı olmadığı halde, hala Türk kahvesi adıyla anılmaktadır. Bölgesel ve mahalli farkların olması tabiidir.

Tıpkı Yunanistan örneğinde olduğu gibi, yine muhtemelen bir savaşın Türk kahvesinin ad değiştirmesine etki ettiğini görüyoruz. Bunun sebebi ne olabilir? Yunanistan'da o zaman "düşman" sayılan Türklerle kültürel bağlantıyı kesme niyeti vardı. 
Bosna'da ise durum tümüyle farklıydı. Bize öyle geliyor ki, savaşta da barışta da Bosna'da günlük hayatın ayrılmaz bir parçası olan Türk kahvesi basit bir ad değişikliğiyle bir millî sembol olarak kolayca benimsenebilirdi. Kahve içme siyasî amaçla da kullanılabilecek günlük bir ritüel idi (ve hala öyledir). Ayrıca şu da unutulmamalıdır ki, o yıllarda Türk kahvesi Türkiye'de o kadar da revaçta değildi ve yerini uzun zaman önce (siyah) çaya bırakmıştı.

Ayrıca, bu bağlamda Bosna'daki savaş (1992-1995) ulus inşa etmede önemli bir yer tutan bir "teşkil edici savaş" olarak görülebilir. Genellikle bu tür bir savaşın bir ulusun doğuşuna sebep olduğu varsayılır ve böylece kurtuluş savaşları, bağımsızlık savaşları ve de bazen iç savaşlar sık sık ulusların doğuşu olarak kabul edilir. Bu yüzden Boşnak kahvesinin doğuşu belki de son savaş sırasında ve sonrasında modern Bosna ulusunun yeniden doğuşu ile ilişkilendirilebilir.

Bir sanat yerleştirmesi (enstalasyon) kahve içme ritüeli ve savaş arasındaki ilişkiyi yansıtması bakımından oldukça ilginç bir örnek sergiler: 11 Temmuz 2004'te, yani 1995 Srebrenitsa soykırımının 9. yıldönümünde sanatçı Aida Šehović soykırımda öldürülen yaklaşık 8.000 erkeği anmak için Saraybosna'da bir cami önünde "Što te nema" (Neden Burada Değilsin) başlıklı bir sanat gösterisi sergiledi. İnsanlardan topladığı 939 kahve fincanını Bosna-Hersek haritası biçiminde düzenlenmiş bir parça toprak üzerine yerleştirdi. Yan tarafta kahve hazırlayarak yavaşça fincanlara döktü. Bazı fincanlara ise, kahve içmek için çok küçük yaşta olan soykırım kurbanı çocukları anmak için, sadece birer küp şeker koydu. Šehović'e göre, bir fincan kahveyi paylaşmak "köklü bir ritüeldir ve ölmüş birisiyle bir fincan kahveyi paylaşma arzusu yürekten bir matem ifadesidir" (Halevy, 2011: s. 68).

Aida Šehović benzeri bir gösteriyi bir yıl sonra New York'ta Birleşmiş Milletler Ana Merkezi'ndeki Ziyaretçi Lobisi'nde gerçekleştirdi (UN News, 2005). Bu tören 10 yıl önce Güvenlik Konseyi'nin ilan ettiği "güvenli bölge"de öldürülen binlerce Boşnağı anmak içindi. Bu sefer, sayılarının 8.000 civarında olduğu tahmin edilen soykırım kurbanlarından cesetleri teşhis edilip yeniden gömülen kişileri temsil etmek için, 1700 beyaz fincan vardı. Aslen Srebrenitsa ve civarından olup da savaş dolayısıyla ABD'ye gelmiş olan Bosnalı ailelerden toplanan fincanların sergilenmesi Bosna'daki kahve içmek için bir araya gelme geleneğinden ilham alıyordu. 11-15 Temmuz 1995'te beş gün boyunca yapılan katliamı temsilen, serginin ilk beş gününde kahve hazırlandı ve Bosna-Hersek haritasını gösteren bir toprak parçasının etrafında insanlara sunuldu. Fincanlar haritanın doğu kısmında Srebrenitsa bölgesinde yanyana durdu. Yine savaşta ölen ve kahve içmek için çok küçük olan çocukları temsilen 44 fincanda sadece küp şekerler vardı. Kahve kokusu etrafa yayılırken, sanatçı hazırladığı ses kaydıyla kurbanların ad ve doğum tarihlerini okudu. Ayrıca, Bosnalı fotoğrafçıların çektiği 40 fotoğraf sergilendi.

\section{SONUÇ}

$\mathrm{Bu}$ çalışma bir içeceğin (Türk kahvesinin) siyaset ve dinle olan ilginç ve zengin ilişkisini ele aldı. Kanaatimce, Türk kahvesi daha en başta (16. yüzyıl ortalarında) İstanbul'da "siyasî" bir içecekti veya bir başka deyişle siyasîleştirildi, çünkü içeceğe ve tüketildiği mekanlara çoğu zaman siyasî anlamlar yüklendi. O devirlerde kahvehanelerde siyasî tartışmalar yapılıyordu ancak bu tür sohbetler onlardan şüphelenen ve onları mevcut toplum ve siyaset düzenine tehdit olarak gören yönetici ve memurları çok rahatsız ediyordu. Üstelik, bu sohbet, tartışma ve söylentiler kamuoyunu etkileyen ve yönlendiren önemli bir 
araçtı. Dahası, Yeniçeri kahvehanelerinin açılmasıyla, bu mekanlar bir tür muhalefet merkezleri olmaya başladı, çünkü Yeniçeriler yöneticilere ve hatta sultana olan muhalefetlerini açıç̧a dile getiriyor, bazen şiddete başvuruyor ve hatta beğenmedikleri sultanları tahttan indiriyorlardı. Bu yüzden yetkililer fitne merkezleri olarak gördükleri kahvehaneleri sık sık kapattılar ve hatta bazen yıktırdılar. Ne var ki, hem kahve hem de kahvehane bu tür saldırılardan sağ çıktı ve imparatorluğun her yerinde yayılmaya başladı.

Türk kahvesi İstanbul ve Kahire'den Güney ve Batı Avrupa'ya yayıldığında, başlangıçta çok benzer tepkilerle karşılaştı. Yeni içecek Türk, Arap veya Müslüman sayıldı ve bu yüzden gayri-Hristiyan, putperest veya şeytani bir içecek olarak görüldü. Bu bakımdan kahvenin Avrupa'daki yayılma sürecinde yaygın olarak İslamofobi'nin bir aracı haline geldiğini söylemek mümkündür. Kahvehaneler siyasi tavırlardan da payını aldı: Tıpkı İstanbul'da olduğu gibi, Britanya'da da (ki bu çalışmada Avrupa ülkelerinden en çok buna ağırlık verdim) bu mekanlar siyasî yıkıcılık ve fitne ile özdeşleştirilip resmi suçlama ve baskıların hedefi oldular. Buna rağmen, bu ülkede de kahve ve kahvehaneler yayılıp serpildi. Hem İstanbul'da hem de Londra'da kahve ve kahvehanelere sözde "dînî" sebeplerle karşı çıkılmasının ardında aslında siyasi sebepler vardı, zira yeni bir tür kamusal alan olarak ortaya çıkan kahvehaneler sıradan insanların siyaset konuştuğu ve tartıştığı ve yolsuzlukları eleştirdiği mekanlar haline geldi. Bu durum seçkinler tarafından hiyerarşik toplum düzenine aykırı görülüp yerleşik düzeni tehdit eden bir gelişme olarak algılandı ve bu yüzden kahve ve kahvehaneler iktidar sahiplerinin gazabına uğradı. Ancak zamanla kahve ve kahvehaneler mücadeleyi kazanan taraf oldu ve toplum ve siyaseti etkilemeyi ve de onlar tarafından etkilenmeyi sürdürdü. Aslında, gördüğümüz kadarıyla, kahve ve kahvehanenin İstanbul ve Londra'da başlangıçta karşılaştığı tutum ve sonraki yayılışı birbirine o kadar çok benziyor ki, o devirlerde bu iki şehirdeki kültür ve toplumların bu bakımdan neredeyse aynı olduğu sanılabilir. Bu konuda daha ayrıntılı bir karşılaştırmalı çalışmanın yapılması gerektiğine inanıyoruz.

Bu çalışmanın ikinci kısmı, 20. yüzyıl sonlarında siyaset ve milliyetçilik dolayısıyla, Türk kahvesinin Yunan ve Boşnak kahvesine dönüştüğü iki örnek üzerinde durdu. Büyük ölçüde, 1960'larda ve 1970'lerde Türkiye ile Yunanistan arasında Kıbrıs sorunu konusunda yaşanan siyasî problemlerden dolayı ve özellikle de 1974'te Türk ordusunun Kıbrıs'taki müdahalesinden sonra, Yunanistan'da Türk kahvesi adını Yunan kahvesine bıraktı. Benzeri bir isim değişikliği Bosna Hersek'te de gerçekleşti ve öyle görünüyor ki, Boşnak kahvesi terimi bu ülkede özellikle 1992-95'teki savaşın ardından yaygınlaşmaya başladı. Her iki ülkede de millîleştirilen kahve millî kültür ve kimliğin güçlü bir sembolü haline geldi. Yunanistan ve Bosna örneklerinde siyasetin kendi davası için gastronomi dahil, gündelik hayatı nasıl biçimlendirdiğine şahit oluyoruz. Son olarak, Yunanistan ve Bosna'da Türk kahvesinin millîleştirilmesi hakkında, bu iki ülkenin millî dillerinde yazılmış literatürün incelenmesiyle daha ileri düzeyde bir araştırma yapılması gerektiğini belirtelim.

\section{SUMMARY}

This article deals with the interesting and rich relationship of a drink (Turkish coffee) to politics and religion. I suggest that Turkish coffee was a "political drink" or was politicized in its earliest time (mid-sixteenth century) in Istanbul, because political meanings were often attached to the drink and the places where it was consumed. In those times, various political discussions took place in coffeehouses and they included criticism of policies, appointments and dismissals, corruption of politicians as well as rumors. Such 
conversations disturbed rulers and officials who were quite suspicious of them and perceived them as a threat to the existing socio-political order. Further, those conversations and sharing of rumors were an important medium for influencing and directing the public opinion. Moreover, with the opening of the coffeehouses by the Janissaries, coffeehouses even began to become akin to opposition centers, as these elite soldiers could openly express their opposition to rulers and even to the sultan and sometimes resort to violence, which included replacing the sultans they did not like. The corruption of the Janissaries as well as their mafia activities made the coffeehouses into easy targets of the officials. That is why, the authorities often closed down and sometimes even demolished the coffeehouses, which they saw as centers of sedition. In addition to the official disdain of the coffeehouses, some jurists and religious leaders too criticized and condemned coffeehouses and coffee and even issued fatwas against coffee and declared it forbidden on religious grounds. Nevertheless, both coffee and coffeehouses survived these attacks and continued to spread all over the empire. Later on, most people, including the political elite, Sufis and men of religion began to enjoy coffee and to frequent coffeehouses.

When the Turkish coffee spread from Istanbul and Cairo to Southern and Western Europe, initially it faced rather similar negative reactions. The drink was considered Turkish, Arabic or Muslim and thus unchristian, heathenish, or satanic. The coffeehouses too got their share: just like in Istanbul, in Britain (which I discussed in the present work more than other European countries) they were also often associated with political subversion and sedition and became targets for official blame and suppression. However, once again, both coffee and coffeehouses survived and flourished. In fact, I should admit that as far as I can see, the initial reception and later spread of coffee and coffeehouses in Istanbul and London bear such striking similarities that one might imagine that the culture and society of these two cities in those times were almost identical in that respect.

The second part of the article dwells on two late twentieth-century cases in which Turkish coffee became Greek and Bosnian coffees respectively due to politics and nationalism. Mostly because of political problems between Turkey and Greece over the Cyprus issue in the 1960s and 1970s and especially after the Turkish military intervention in Cyprus in 1974, Turkish coffee was renamed Greek coffee in Greece. A similar renaming occurred in Bosnia and Herzegovina and apparently the term Bosnian coffee became widespread in the country particularly after the war in Bosnia in 1992-95. In both cases, nationalized coffee became a strong symbol for national culture and identity.

In brief, Turkish coffee provides a very striking and colorful example of the relationship between a drink and politics as well as religious culture in Europe since its arrival at the southeastern-most part of the continent, namely Istanbul. The first part of the present work shows how a newly introduced drink (Turkish coffee) involved the state (and politics) as well as religion both in the Ottoman capital and Christian Europe. Thus, this part is more about a drink influencing the politics and culture in the lands where it spread. Yet, the second part of the work reflects just the reverse: in the Greek and Bosnian cases, one witnesses how politics shapes to its purposes the everyday language, including gastronomy. We observe how a simple drink, namely Turkish coffee, becomes an object of national identity and national pride by merely assuming a national name.

SEFAD, 2019; (41): 369-386 


\section{KAYNAKÇA}

A Satyr against Coffee (1674). Londra. http://name.umdl.umich.edu/A62192.0001.001 adresinden erişildi.

Bach, J. S. (2018, 23 Eylül). Kaffeekantate. Erişim adresi: http://www.bachcantatas.com/Texts/BWV211-Eng3.htm

Bland, A. (2014). As espresso rises, will 'Greek coffee' be left to the Turks?. National Public Radio. Erişim adresi http://www.npr.org/sections/thesalt/2014/11/18/364140082/asespresso-rises-will-greek-coffee-be-left-to-the-turks

Bostan, İ. (2001). Kahve. TDV İslam Ansiklopedisi. C. XXIV (s. 202-205). İstanbul: Türkiye Diyanet Vakfı Yayınları.

Browning, R. (1983). Medieval and modern Greek. Cambridge-New York: Cambridge University Press.

Câbî Ömer Efendi. (2003). Câbî târihi (târîh-i Sultân Selîm-i Sâlis ve Mahmûd-ı Sânî) (2. Cilt). M. A. Beyhan (Ed.). Ankara: Türk Tarih Kurumu.

Charles. (1675). A proclamation for the suppression of coffee-houses. Londra: John Bill and Christopher Barker.

Chazot, S. (2015). Robert Ménard lutte contre les kebabs à béziers parce que la France est un pays de 'tradition judéo-chrétienne'. Europe1. Erişim adresi: http://lelab.europe1.fr/robert-menard-lutte-contre-les-kebabs-a-beziers-parce-que-lafrance-est-un-pays-de-tradition-judeo-chretienne-2539397

Coffeefair Serbia. (2014). Kako se kuva domaća kafa. Erişim adresi: http://www.coffeefair.rs/kako-se-kuva-domaca-kafa

Cohen, B. (2014). The complicated culture of Bosnian coffee. BBC Online. Erişim adresi: http://www.bbc.com/travel/story/20140707-the-complicated-culture-of-bosnian-coffee

Cowan, B. (2005). The social life of coffee: The emergence of the British coffeehouse. New Haven: Yale University Press.

Crawford, J. (1852). History of coffee. Journal of the Statistical Society of London, 15 (2), 50-58.

Çaksu, A. (2007). The janissary coffeehouses in the late $18^{\text {th }}$ century Istanbul. D. Sajdi içinde, Ottoman Tulip, Ottoman Coffee: Leisure and Lifestyle in 18 ${ }^{\text {th }}$ Century (s. 117-132). LondraNew York: I.B. Tauris.

Çaksu, A. (2014). Onsekizinci yüzyıl sonu İstanbul yeniçeri kahvehaneleri. (A. Onacak, Çev.). D. Sajdi içinde, Osmanlı Laleleri, Osmanlı Kahvehaneleri: On Sekizinci Yüzyılda Hayat Tarzı ve Boş Vakit Eğlenceleri (s.151-173). İstanbul: Koç Üniversitesi Yayınları.

Everard. (1672). A broadside against coffee: Or the marriage of the Turk. The Vertue of Tobacco. Erişim adresi: http://home.gwu.edu/ klarsen/broadside.html

Fotić, A. (2011). The introduction of coffee and tobacco to the Mid-West Balkans. Acta Orientalia Academiae Scientiarum Hungaricae, 64 (1), 89-100.

Greek Reporter. (2012). Greek-Turkish coffee wars ensnare UNESCO. Erişim adresi: http://greece.greekreporter.com/2012/11/22/greek-turkish-coffee-wars-ensnare-unesco.

Habermas, J. (1991). The structural transformation of the public sphere: An inquiry into a category of bourgeois society. Cambridge, MA: MIT University Press.

Halevy, A. Y. (2011). The infinite emotions of coffee. USA: Macchiatone Communications, LLC. 
Hattox, R. C. (1996). Coffee and coffee houses: The origins of a social beverage in the medieval near east. Washington: University of Washington Press.

Heise, U. (1987). Coffee and coffee-houses. Atglen: Schiffer Publishing.

Hering, C. G. (2018, 23 Eylül). Der Kaffee-Kanon. Erişim adresi: http://www.musicanet.org/robokopp/Lieder/kaffeeli.html

Işın, P. M. (2014). Osmanlı mutfak imparatorluğu. İstanbul: Kitap Yayınevi.

Kafadar, C. (1981). Yeniçeri-esnaf relations: Solidarity and conflict (Yüksek Lisans Tezi) Montreal: McGill Üniversitesi.

Karakatsanis, L. (2014). Turkish-Greek relations: Rapprochement, civil society and the politics of friendship. Londra-New York: Routledge.

Kırbaki, Y. (2015, 24 Mart). Türk kahvesi-Yunan kahvesi. Hürriyet. Erişim adresi: http://sosyal.hurriyet.com.tr/yazar/yorgo-kirbaki_136/turk-kahvesi-yunankahvesi_27309182

Kırlı, C. (2000). Kahvehaneler ve hafiyeler: 19. yüzyıl ortalarında Osmanlı'da sosyal kontrol. Toplum ve Bilim, 83, 58-79.

Koçu, R. E. (1964). Yeniçeriler. İstanbul: Koçu Yayınları.

Maclean, G. ve Matar, N. (2011). Britain and the Islamic world, 1558-1713. Oxford: Oxford University Press.

Malecka, A. (2015). How Turks and Persians drank coffee: A little-known document of social history by father T. J. Krusiński. Turkish Historical Review, 6, 175-193.

Matar, N. (1998). Islam in Britain, 1558-1685. Cambridge: Cambridge University Press.

Mehmed Dâniş Bey. (1994). Netîcetü'l-vekayi'. yeniçeri ocağının kaldırılışı ve II. Mahmud'un Edirne seyahati: Mehmet Dâniş Bey ve eserleri. Ş. Mutlu (Ed.). İstanbul: Edebiyat Fakültesi Basımevi.

Mikes, G. (1965). Eureka! rummaging in Greece. Londra: Andre Deutsch.

Miller ve diğerleri. (2012,14 Ekim). Greek anti-austerity protesters hurl coffee at German diplomat as riots sweep across Europe. Daily Mail. Erişim adresi: http://www.dailymail.co.uk/news/article-2232706/Greek-anti-austerity-protesters-hurlcoffee-German-diplomat-riots-sweep-Europe.html.

Mlekuž, J. (2008). Predmet kot akter? primer bureka v Sloveniji (Doktora Tezi). Nova Gorica: Nova Gorica Universitesi. http://www.ung.si/ library/doktorati/interkulturni/4Mlekuz.pdf adresinden erişild.

Mlekuž, J. (2015). Burek a culinary metaphor. Budapeşte-New York: CEU Press.

Naîmâ, M. E. (1281-83). Târîh-i naîmâ: Ravdat-ül Hüseyn fî hülâsat-i ahbâr-il hâfikeyn (3. bs.). İstanbul: Matbaa-i Âmire. 3. bs.

Pavlidis, V. (2013). Turkikos kafes. Iporta Magazine. Erişim adresi: https://iporta.gr/62toyrkikos-kafes-tou-vaggeli-pavlidi/

Petropoulos, E. (1995). Yunanistan'da Türk kahvesi (Herkül Millas, Çev.). İstanbul: İletişim Yayınları.

Petropoulos, I. (1979). O Turkikos kafes en eladi. Atina: Ekdoseis Nefeli.

Şânîzâde, A. (t. y.). Târîh-i Şânîzâde (4 Cilt). I: İstanbul: y.y. 1284. II: İstanbul: Süleyman Efendi Matbaası. 1290. III: İstanbul: y.y. 1291. IV: İstanbul: Cerîde-i Havâdis Matbaası.

SEFAD, 2019; (41): 369-386 
The Character of a Coffee-House. (1665). Erişim aderesi: http://name.umdl.umich.edu/A31685.0001.001

The Mens Answer to the Womens Petition against Coffee. (1674). Erişim adresi: Londra. http://www.staff.uni-giessen.de/gloning/tx/mens-answer-1674.htm

The Women's Petition against Coffee. (1674). Londra. Erişim adresi: http://www.staff.unigiessen.de/gloning/tx/wom-pet.htm

Trivolis, D. (2013). Ask CB: Greek coffee in athens?. Culinary Backstreets. Erişim adresi: http:/culinarybackstreets.com/cities-category/athens/2013/greek-coffee-in-athens/

Tsolakidou, S. (2012). Frappé: the history of coffee that Greeks are obsessed with. Greek Reporter. Erişim adresi: http://greece.greekreporter.com/2012/05/19/frappe-the-historyof-coffee-that-greeks-are-obsessed-with

Twain, M. (1869). The innocents abroad. Hartford: American Publishing Company.

UN News. (2005). Srebrenica: Traditional Bosnian coffee ritual honours massacre victims at UN. http://www.un.org/apps/news/story.asp?NewsID=14990\&Cr=Srebrenica\&Cr1 adresinden erişildi.

UNESCO. (2013). Turkish coffee culture and tradition. Erişim adresi: http://www.unesco.org/culture/ich/en/RL/turkish-coffee-culture-and-tradition-00645

Ünal, A. (2015,17 Nisan). A new step forward in bilateral relations after 'Turkey and Serbia in the 21st century' conference. Daily Sabah. Erişim adresi: http://www.dailysabah.com/diplomacy/2015/04/17/a-new-step-forward-in-bilateralrelations-after-turkey-and-serbia-in-the-21st-century-conference

Young, D. (2013). “The history of Greek-style frappe. I Need Coffee. Erişim adresi: https://ineedcoffee.com/the-history-of-greek-style-frappe/ [23.9.2018]. 